\title{
TESTANDO AS PREVISÕES DA PECKING ORDER THEORY NO FINANCIAMENTO DAS EMPRESAS BRASILEIRAS: UMA NOVA METODOLOGIA
}

\section{TESTING THE PECKING ORDER THEORY FORECASTS IN BRAZILIAN COMPANIES FINANCING: A NEW METHODOLOGY}

\author{
ROBERT ALDO IQUIAPAZA \\ Doutorando em Administração pela Universidade Federal de Minas Gerais (UFMG). \\ Pesquisador, Bolsista do CNPq, no Centro de Pós-graduação e Pesquisa em Administração \\ da Universidade Federal de Minas Gerais (CEPEAD/UFMG). \\ Av. Antônio Carlos, 6627, Prédio FACE, NUFI/Laboratório de Finanças, Pampulha \\ Belo Horizonte - MG - CEP 31270-901 \\ E-mail: raic@face.ufmg.br
}

HUDSON FERIANDES AMARAL

Doutor em Sciences de Gestion pela Université Pierre Mendés France (Grenoble II - France). Coordenador do Programa de Pós-graduação do Centro de Pós-graduação e Pesquisa em Administração da Universidade Federal de Minas Gerais (CEPEAD/UFMG). Av. Antônio Carlos, 6627, Prédio FACE, bloco 1, $4^{\circ}$ andar, sala 4030, Pampulha Belo Horizonte - MG - CEP 31270-901 E-mail:hfamaral@face.ufmg.br

MARINA DA SILVA BORGES DE ARAÚJO Bacharel em Ciências Econômicas pela Universidade Federal de Minas Gerais (UFMG). Pesquisadora/Economista da Fundação Dom Cabral. Rua Astolfo Dutra, 246, Pompéia Belo Horizonte - MG - CEP 30280-420 E-mail: marinasba@gmail.com 


\section{RESUMO}

Considerando a existência de assimetria de informação entre gestores e investidores, Myers (1984) afirma que a formação da estrutura de capital por parte das empresas está baseada em uma hierarquia de captação conhecida como Pecking Order Theory (POT), favorecendo seqüencialmente a utilização de recursos internos, emissão de dívida e, por último, emissão de ações. A verificação empírica esbarra em questões metodológicas, sendo a POT por vezes confirmada e outras negada. Neste artigo, propõe-se uma metodologia diferente, reconhecendo as características das empresas como tamanho, lucratividade e crescimento, para explicar o financiamento do déficit, utilizando um modelo de dados em painel. Analisou-se uma amostra de 313 empresas listadas na Bovespa de 2000 a 2005. Os resultados indicam que unicamente as empresas de menor tamanho na amostra, de lucratividade negativa e baixo crescimento, apresentam aderência (fraca) às previsões da POT. Assim, essa teoria não pode ser considerada uma teoria geral para explicar a estrutura de capital das empresas.

\section{PALAVRAS-CHAVE}

Pecking Order; Estrutura de financiamento; Lucratividade; Tamanho das empresas; Crescimento dos ativos.

\section{ABSTRACT}

Considering the existence of asymmetric information between managers and investors, Myers (1984) affirms that the configuration of corporate capital structure is based on a hierarchy known as Pecking Order Theory (POT), favoring sequentially the use of internal resources, debt emission and, at last, stocks issues. The POT's empiric verification breaks up into methodological matters; some times being confirmed and other does not. In this article a different methodology is proposed recognizing the characteristics of companies such as size, profitability and 
growth, to explain the financing of the deficit. The results indicate that only the smaller size companies in the sample, negative profitability, and lower growth present a weak adherence to the POT's forecasts. For this reason this cannot be considered a general theory to explain the corporate capital structure.

\section{KEYWORDS}

Pecking Order; Capital structure; Profitability; Enterprise size; Growth of the assets.

\section{INTRODUÇ ̃̃O}

Uma questão de relevância no campo das finanças está na decisão dos executivos por formas de financiamento para as atividades empresariais. A decisão da estrutura de capital a ser utilizada situa-se na escolha entre o emprego do capital próprio e a utilização do capital de terceiros. Ou seja, o financiamento da atividade empresarial ocorrerá a partir dos mercados de crédito, de capitais e da geração de recursos pela própria empresa.

Assim, a estrutura de capital de uma empresa pode ser definida como um conjunto dos títulos usados para financiar as atividades empresariais, ou, ainda, como a razão entre as dívidas de curto, médio e longo prazos e o capital próprio (MYERS, I984). De acordo com Myers (1984) e Gitman (I997), a decisão da forma de financiamento pelos administradores envolve duas problemáticas principais. A primeira está relacionada à proporção entre o financiamento de curto e de longo prazos. A segunda problemática já envolve decisões sobre quais fontes de financiamento utilizar no curto e no longo prazos.

Myers (I984) e Harris e Raviv (I99I) afirmam que existe uma grande dificuldade em se estabelecer um modelo geral e único de estrutura de capital, pois este seria extenso e complexo. A proposta desses autores é que os pesquisadores busquem a formulação de modelagens particulares, que tentem captar as necessidades de cada setor ou de cada estrutura de capital. Além disso, eles apontam como determinantes da escolha por determinada estrutura de capital: custo de agência; informação assimétrica; influência da natureza dos produtos ou competição dos mercados de produtos e de insumos; conflitos pelo poder ou comando da empresa; e balanceamento entre custos de falências e dedutibilidade dos juros no pagamento de impostos.

Myers (1984), considerando a existência de assimetrias de informação entre gestores (insiders) e investidores, afirma que a formação da estrutura de capital 
por parte das empresas está baseada na idéia de que estas possuem uma hierarquia, lógica e racional, de captação de fontes de financiamento. Segundo essa hierarquia, conhecida como Pecking Order Theory (POT), a empresa em questão optaria, sempre que possível, por financiar-se com recursos gerados internamente. Caso esses recursos não fossem suficientes para sustentar a atividade empresarial, essa empresa passaria a emitir dívida e, por último, tomaria a decisão de emitir ações (MYERS; MAJLUF, I984; FRANK; GOYAL, 2003; FAMA; FREN$\mathrm{CH}, 2005)$.

Os estudos para a verificação empírica das previsões da POT usualmente utilizam uma amostra representativa de companhias, por meio da análise das informações primárias e secundárias dessas empresas. Com esse intuito, a modelagem de séries temporais ou de dados em painel é preferida (FRANK; GOYAL, 2003; FAMA; FRENCH, 2002). De acordo com Chirinko e Singha (2000) e Fama e French (2005), o problema com essa metodologia é que se ignoram as características heterogêneas das empresas, fazendo uma análise para a empresa média ou representativa, o que pode levar a resultados enviesados.

Este artigo visa propor uma nova metodologia focada nas características das empresas como tamanho, lucratividade e crescimento dos ativos, a fim de identificar a aderência, ou não, do financiamento das empresas do mercado bursátil brasileiro às previsões da POT.

\section{ASSIMETRIA DE INFORMAÇÃO E PECKING ORDER THEORY}

Genericamente, o termo "assimetria de informação" refere-se, em uma dada transação, às informações privilegiadas que somente um dos agentes atuantes possui. Akerlof (I970), em um artigo pioneiro, estabeleceu o quanto a assimetria de informação pode influenciar no equilíbrio do mercado. Outros trabalhos que se destacaram pela abordagem da assimetria correspondem a Stiglitz e Weiss (I98I), Myers (I984) e Myers e Majluf (I984). Stiglitz e Weiss (I98I) abordaram os efeitos da seleção adversa na determinação do mercado de crédito, e Myers e Majluf (I984) trataram das assimetrias de informação relacionadas com a estrutura de capital das empresas e a emissão de ações.

Stiglitz e Weiss (I98I) e Myers (I984) afirmam que, no mercado financeiro, a informação é fundamental para o seu bom funcionamento. Seria por meio dessa informação plena que os agentes atuariam de forma mais eficiente e com menores riscos. Mas, no mercado, o acesso à informação é difícil e seletivo. Myers (I984) confirma que esse caso caracteriza a existência de imperfeições no mercado de capitais. 
Myers e Majluf (I984) foram pioneiros em relacionar a problemática da assimetria de informação à escolha da estrutura de capital, assinalando que esta pode influenciar na imagem e no valor da empresa. Eles concluem que, em geral, novas emissões repassam ao mercado uma imagem negativa da empresa. Imagem essa relacionada à não-capacidade de se autofinanciar e à impossibilidade de conseguir empréstimos no mercado. Pelo mesmo motivo, os investidores potenciais impõem sobre o preço da ação um ágio, que busca diminuir a suposta sobrevalorização desta. Assim, a assimetria de informações leva os acionistas potenciais a questionarem os motivos que fizeram a empresa buscar financiamento com emissão de ações (FAMA; FRENCH, 2005; FRANK; GOYAL, 2003).

Donaldson (I96I), corroborando as idéias de Myers e Majluf (I984), afirma que as decisões dos administradores e acionistas, no que tange à estrutura de capital, seguem uma hierarquia, buscando maximizar os interesses tanto da administração como dos acionistas. Esse autor justifica essa hierarquização por meio do fortalecimento da administração dentro da empresa, fazendo com que esta seja capaz de gerar lucros suficientes para o pagamento de dividendos e para a retenção (visando ao reinvestimento).

A idéia central da POT surge quando os gestores da empresa decidem por uma forma de financiamento para as atividades empresariais. Nesse momento, eles devem considerar diversos fatores como os custos de capital, as condições de mercado e os interesses dos acionistas. Mas o fator mais importante é o impacto da assimetria informacional na imagem da empresa - tanto para seus acionistas, como para os acionistas potenciais e os agentes do mercado de crédito. De acordo com as previsões da POT, a captação de recursos por intermédio da emissão de ações seria a última e pior escolha dos tomadores de decisão, por causa de uma possível subprecificação que estas empresas podem vir a sofrer. Segundo Myers e Majluf (I984), Myers (I984) e Frank e Goyal (2003), a subprecificação ocorreria em casos em que o conjunto de informações detidas pelos investidores potenciais fosse menos rico do que as detidas pelos gestores. Assim, diante de um menor grau de informação, os investidores potenciais tratariam os preços das ações, quando estas fossem lançadas no mercado, como superestimados. Conseqüentemente, seguindo a lógica dos investidores potenciais, estes somente comprariam tais ações quando fossem ofertadas com desconto no mercado. Neste momento ocorre a subprecificação. A desvantagem dessa subprecificação para os administradores é a ocorrência de um subinvestimento nas empresas. Além disso, pela assimetria de informação no mercado, há uma transferência de riqueza dos investidores antigos para os novos investidores.

As empresas mais lucrativas tenderão a usar o dinheiro gerado internamente como financiamento - o que diminui o seu coeficiente de endividamento -, e as empresas menos lucrativas tenderão a utilizar a emissão de dívida como a melhor 
fonte de recursos - diante de sua incapacidade de se autofinanciar, elas terão maiores índices de endividamento (PEROBELLI; FAMÁ, 2002; FAMA; FREN$\mathrm{CH}, 2005)$.

Ainda segundo a fundamentação teórica de Pecking Order, as empresas optarão pela emissão de dívida em detrimento a novas emissões de ações porque o deságio é menor, e o benefício da dedução dos juros pagos é de interesse delas. Entretanto, no caso do Brasil, a existência de praticamente um único ofertante de recursos para crédito em longo prazo (ainda, o BNDES não está disponível para todas as empresas) e de taxas de juros de longo prazo menores que as taxas de juros de curto prazo dificulta a efetivação da POT (MEDEIROS; DAHER, 2004). Outra vantagem da emissão de dívida é que, como os portadores de títulos de dívida têm um retorno esperado, os acionistas não precisam partilhar seus lucros futuramente. Já as desvantagens da utilização do capital de terceiros estão relacionadas com o grau de endividamento da empresa que aumenta os custos de captação, ou juros a serem pagos, pela menor taxa, e a credibilidade da empresa no mercado.

Segundo Chirinko e Singha (2000) e Frank e Goyal (2003), a POT admite duas formas básicas, a forte e a semiforte (ou fraca). Sob a forma forte, as empresas optam por somente duas fontes de financiamento - o uso de recursos internos e a emissão de dívida -, não cogitando a possibilidade da emissão de ações. Já na forma semiforte (ou fraca) é considerada a possibilidade de emissão de ações, porém sem que estas transgridam os pressupostos teóricos apresentados.

Na modelagem da POT, para alguns autores, a emissão de ações não é rejeitada completamente. Entretanto, há duas ocasiões em que essa emissão é plausível. A primeira delas é quando a empresa precisa de uma reserva financeira para eventos futuros não-previstos (MYERS; MAJLUF, I984; FRANK; GOYAL, 2003). Já a segunda é quando a assimetria de informações não existe, pelo menos momentaneamente, por qualquer motivo que seja. Nesse último caso, as ações emitidas não sofreriam as subprecificações decorrentes das expectativas de sobrevalorização dos acionistas potenciais, sendo negociadas a um preço justo (MYERS, I984; FAMA; FRENCH, 2005).

Frank e Goyal (2003) analisaram as conclusões de Shyam-Sunder e Myers (I999) e encontraram alguns problemas na modelagem empírica da POT. Em contraposição ao que foi apresentado por Myers, as empresas comumente utilizam recursos de terceiros (emissão de dívida), já que a retenção interna de lucros mostra-se insuficiente para financiar os projetos das empresas. Outro ponto levantado é o aumento do número de empresas médias. Estas possuem capacidade reduzida de financiamento próprio, o que torna a emissão de dívida e de ações uma das formas mais viáveis de financiamento. Este mesmo argumento justifica realizar uma análise agrupando as empresas segundo características similares. 
Alguns autores brasileiros como Medeiros e Daher (2004) e Silva e Brito (2005), em seus trabalhos empíricos da POT para empresas brasileiras, comprovaram o comportamento destas de acordo com as predições da POT. Nesses casos foram realizados testes para avaliar a existência da POT em contraposição à existência de uma outra linha teórica - a Static Trade-off. Foram encontrados resultados que favoreciam a existência da POT.

Entretanto, Fama e French (2005), seguindo uma nova metodologia de análise da estrutura de financiamento das empresas, apresentaram resultados que rejeitavam as predições da POT, sustentando que essas empresas vendem e recompram ações com maior freqüência do que o previsto por essa teoria. Esses autores afirmam que, em razão do aparecimento de diversas práticas que desviam as empresas de escolhas por estruturas de financiamento segundo a POT (por exemplo, colocação privada, aquisição por intercâmbio de ações, dívida conversível, warrants, as fontes alternativas de pagamento de salários seja em ações seja em opções, incluso com empréstimos, planos de benefícios, além da modernização do mercado de capitais), essa teoria vem se tornando inconsistente no atual contexto corporativo das empresas. Mas vale ressaltar que os resultados apresentados por esses autores foram calculados para empresas que funcionam em um contexto econômico diferente da realidade brasileira.

\section{METODOLOGIA}

\subsection{AMOSTRA DE ESTUDO}

A amostra foi composta por empresas negociadas na Bolsa de Valores de São Paulo, que tiveram suas ações negociadas em pelo menos cinco dos seis anos analisados (de 2000 a 2005). Nessa fase foram levantadas 502 empresas.

$\mathrm{Na}$ segunda fase, foram excluídas as empresas com informações descontínuas; empresas que apresentassem para os anos de 2004 e 2005 ativos totais com valores inferiores de cinco milhões de reais; empresas com problemas financeiros; em processos de fusão; e as envolvidas em processos de reorganização societária ou administração judiciária por acreditar-se que essas circunstâncias levam as empresas a posições desfavoráveis nos mercados (perda de credibilidade). Após esses critérios, formou-se um banco de dados com 313 empresas a serem analisadas segundo os critérios apresentados a seguir.

As informações sobre as variáveis financeiras utilizadas no estudo foram extraídas do banco de dados Economática $®$, trabalhadas estatisticamente no software Stata $9 \circledR$. Todas as variáveis financeiras foram corrigidas pela inflação de 3I de dezembro de 2005 (último período analisado). Assim, todas as análises baseiam-se em valores reais e em suas variações reais. 


\subsection{MODELO E VARIÁVEIS}

A idéia central da POT é que, quando o fluxo de caixa interno da empresa é insuficiente para sustentar as intenções de investimento desta, a empresa emite preferencialmente dívida. Teoricamente, as emissões de ações representam o último recurso de financiamento de uma empresa e, pelo mesmo, raramente ocorrem. Espera-se, portanto, que a empresa que apresente algum déficit financeiro o financiará com emissão de dívidas, e nunca com emissões de ações.

Considera-se o déficit financeiro como o montante de recursos financeiros demandados pela empresa para dar prosseguimento às atividades empresariais não-supridas pela sua capacidade interna de geração de recursos (lucros retidos acumulados). É a capacidade dos fluxos de caixa gerados de liquidar os dividendos a serem pagos, de promover os investimentos a serem realizados e de sustentar as variações de capital de giro. Caso esses fluxos sejam insuficientes para cobrir as necessidades da empresa, esta terá um déficit financeiro (FRANK; GOYAL, 2003; MEDEIROS; DAHER, 2004). Em termos algébricos, o conceito de déficit pode ser expresso:

$$
D E F_{t}=D I V_{t}+I_{t}+\Delta W_{t}-C_{t} \quad \text { Eq. (I) }
$$

onde:

$D E F_{t}=$ déficit financeiro da empresa;

$D I V_{t}=$ pagamento de dividendos;

$\Delta W_{t}=$ aumento líquido do capital de giro;

$I_{t}=$ investimentos de capital;

$C_{t}=$ fluxo de caixa operacional após juros e impostos.

Como as componentes da Eq. (I) não são facilmente identificáveis, optou-se por uma aproximação diferente. $O$ déficit financeiro da empresa $\left(\mathrm{DEF}_{t}\right)$ foi calculado com base nas variações do ativo total da empresa, subtraindo as variações dos lucros retidos dela. Esse cálculo do déficit nos permite encontrar todos os incrementos de ativo total na empresa gerados por outros recursos que não os lucros retidos, ou seja, que não tenham surgido da própria capacidade da empresa de se autofinanciar. Trata-se de outra ótica, fundamentalmente contábil, apresentada por Fama e French (2005) em que:

$$
D E F_{t}=\left(A_{t}-A_{t-1}\right)-\left(R E_{t}-R E_{t-1}\right) \quad \text { Eq. (2) }
$$

onde:

$A=$ ativos totais da empresa;

$R E=$ lucros retidos da empresa (lucros acumulados mais reservas de lucro). 
Como apresentado por Shyam-Sunder e Myers (1999), Frank e Goyal (2003) e Medeiros e Daher (2004), a POT considera que todos os componentes do déficit são exógenos, desde que dívidas saudáveis (excluídas as junk bonds) possam ser emitidas.

O déficit, após o esgotamento dos recursos internos, somente pode ser financiado com emissão de dívida e/ou ações. Mas, diante do conceito de déficit exógeno e da hipótese de nula emissão de ações (SHYAM-SUNDER; MYERS, I999; FRANK; GOYAL, 2003), as variações do montante do endividamento bruto podem ser explicadas pelo nível de déficit. Assim, o modelo econométrico a ser testado é:

$$
\Delta E n d_{-} \text {bruto }_{t}=\beta_{0}+\beta_{1} D E F_{t}+e_{t} \quad \text { Eq. (3) }
$$

onde:

$\Delta E n d \_b r u t o=$ endividamento bruto, emissão de dívida de curto e longo prazos.

Caso o modelo anterior não seja válido para alguma empresa, esta terá financiado parte do seu déficit por meio da emissão de ações. Por esse motivo, deve ser avaliado conjuntamente o comportamento das emissões de ações ( $d S B=$ Emissões de ações da empresa segundo valores contábeis).

A intenção dessa metodologia de análise é não somente avaliar o comportamento do endividamento segundo as variações do déficit, mas também avaliar o comportamento das emissões de ações no decorrer do tempo. A POT pressupõe que as empresas mais lucrativas teriam níveis de endividamento menores e não emitiriam novas ações no mercado de capitais. Outra característica esperada é que as empresas que apresentem alto crescimento de seus ativos ou que sejam médias em seu tamanho se ajustem melhor à teoria da Pecking Order (MEDEIROS; DAHER, 2004).

Especificamente, para a "forma forte" da POT, espera-se que:

- Para as variações do endividamento: $\mathrm{H}_{0}: \beta_{0}=0$ e $\beta_{1}=1$;

- Para as emissões de ações: que estas sejam nulas ou próximas de zero.

Ou seja, em caso de o déficit financeiro não ser financiado por recursos internos, a empresa usará Io०\% de endividamento para cobri-lo $\left(\mathrm{H}_{0}: \beta_{1}=1\right) \mathrm{e}$ não emitirá ações.

Entretanto, se for levada em consideração a "forma fraca" da POT, certo nível de emissões de ações será aceito, e, portanto, uma redução dos níveis de endivi- 
damento também será plausível (FRANK; GOYAL, 2003; CHIRINKO; SINGHA, 2000). Nesse caso, o coeficiente encontrado deverá ser menor que a unidade, mas será próximo dela.

As variações de endividamento bruto ( $\Delta$ End_bruto ) serão compostas por todas as obrigações da empresa, tanto no longo como no curto prazo. Pelo mesmo, utilizou-se a variação da dívida bruta como representante destas. A justificativa para a utilização dessa variável, e não considerar somente a dívida de longo prazo, se encontra na verificação das dificuldades das empresas em conseguirem financiamento para suas atividades de longo prazo. Grande parte da dívida das empresas em questão está concentrada no curto prazo. A dívida bruta foi determinada da seguinte forma:

$$
\text { End_bruto }=\text { Fin }_{c p}+\text { Dbtres }_{c p}+\text { Fin }_{l p}+\text { Dbtres }_{l p} \quad \text { Eq. (4) }
$$

onde:

End_bruto = saldo do endividamento bruto de curto e de longo prazos;

Fin $_{c p}=$ financiamentos da empresa para o curto prazo;

Dbtres $_{c p}=$ debêntures com vencimento em curto prazo;

Fin $_{l p}$ = financiamentos da empresa para o longo prazo;

Dbtres $_{l p}=$ debêntures com vencimento em longo prazo.

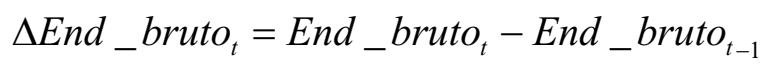

Para a mensuração das emissões de ações (dSB), utilizaram-se as definições das demonstrações contábeis (formalmente essa variável seria a emissão de ações a valores contábeis), fundamentadas nas vantagens assinaladas por Fama e French (2005). Em termos algébricos, a dSB foi expressa por:

$d S B=d S E-d R E$

onde:

$d S E=$ mudança no patrimônio dos acionistas $=$ patr_liq $q_{t}-$ patr_liq $_{\mathrm{t}-1}$;

$d R E=$ mudança nos lucros retidos $=\left({\operatorname{luc} \_a c u_{\mathrm{t}}}_{\mathbf{t}}+r e s_{-} l u c_{t}\right)-\left(\mathrm{luc}_{-} \mathrm{acu}_{\mathrm{t}-1}+\right.$ res_luc $\left.c_{\mathrm{t}-1}\right)$.

Para que seja possível a comparação dos níveis dos déficits, endividamento bruto e emissão de ações das diferentes empresas, todas as variáveis apresentadas foram divididas pelo ativo total correspondente. 


\subsection{CATEGORIZAÇÃO DAS VARIÁVEIS}

Um problema encontrado em trabalhos anteriores que abordaram a existência ou não da hierarquização das fontes de financiamento é que os estudos empíricos eram realizados com base em uma amostra única, o que traz para a análise um grande viés em razão da heterogeneidade das empresas brasileiras. Diferenças essas existentes pelas diferentes condições de competitividade ou de capacidade de investimento delas. Dentre as principais diferenças abordadas por Fama e French (2005), têm-se as considerações de crescimento dos ativos das empresas; as de lucratividade destas; ou então pelas de tamanho das empresas. Em seu trabalho, esses autores afirmam que a comparação de empresas com características muito discrepantes pode gerar resultados enviesados. E visando amenizar os efeitos desse viés nos resultados, foi proposto que a amostra fosse dividida como apresentado a seguir.

\subsubsection{Tamanho da empresa}

A amostra foi categorizada com base no tamanho da empresa, mensurado por meio dos ativos totais (AT). Para cada ano, foi calculada a mediana do ativo e logo se especificaram dois grupos para os subperíodos 2000-2002 e 2003-2005, tendo como limite a média das medianas $(\widetilde{A})$.

$$
A_{00-02}=\frac{\tilde{A}_{00}+\tilde{A}_{01}+\tilde{A}_{02}}{3} \text { e } A_{03-05}=\frac{\tilde{A}_{03}+\tilde{A}_{04}+\tilde{A}_{05}}{3}
$$

Assim, têm-se as empresas de cada período divididas entre médias e grandes empresas.

Tamanho I $=$ Médias empresas: Média do $\mathrm{AT}_{00-02}<=\mathrm{A}_{00-02}$ e Média do $\mathrm{AT}_{03-05}<=\mathrm{A}_{03-05}$ Tamanho 2 = Grandes empresas: Média do $\mathrm{AT}_{00-02}>\mathrm{A}_{00-02}$ e Média do $\mathrm{AT}_{03-05}>\mathrm{A}_{03-05}$

\subsubsection{Lucratividade}

Outra categorização foi por meio da lucratividade da empresa. O lucro operacional Ebit das empresas foi utilizado como forma de classificar essa capacidade de gerar lucros. De modo que:

$$
\mathrm{dE}=\frac{\text { Ebit }_{t}}{A_{t}}
$$


Para isso, calcularam-se as médias da mediana da lucratividade de cada empresa para cada subperíodo, de forma análoga à realizada na categorização do tamanho. A esse valor, comparou-se a relação $\mathrm{dE}$ de acordo com a seguinte regra:

Lucri $=$ empresas com lucratividade negativa $=\mathrm{dE}<0$;

Lucr2 $=$ empresas com baixa lucratividade $=\mathrm{dE}>=0$ e $\mathrm{dE}<=\mathrm{X}$;

Lucr3 $=$ empresas com alta lucratividade $=\mathrm{dE}>\mathrm{X}$;

Sendo $\mathrm{X}$ o resultado da média das medianas de dE em cada subperíodo.

\subsubsection{Crescimento dos ativos da empresa}

As empresas também foram subdivididas em dois grupos segundo o crescimento dos ativos, seguindo um procedimento análogo ao definido para o tamanho. O crescimento dos ativos foi definido como:

$d A=\frac{A_{t}-A_{t-1}}{A_{t}}$

Assim, as empresas foram classificadas de modo que:

CrescI $=$ empresas com baixo crescimento dos ativos $=\mathrm{dA}<\mathrm{X}$;

Cresc2 $=$ empresas com alto crescimento dos ativos $=\mathrm{dA}>\mathrm{X}$;

Sendo $\mathrm{X}$ o resultado da média das medianas calculadas para cada subperíodo.

Com essa caracterização das empresas por subperíodos (I - 2000 a 2002; e $2-2003$ a 2005), espera-se controlar as possíveis influências do contexto econômico na atuação das empresas. Um exemplo de fato relevante para essa divisão é a mudança do mandato presidencial em 2002 . Também permite capturar a dinâmica do contexto competitivo, uma empresa pode eventualmente mudar de categoria de um período para outro.

\subsection{OS MODELOS PARA DADOS EM PAINEL}

Os dados em painel são utilizados pela possibilidade de combinar efeitos de séries temporais com efeitos transversais (cross-section) para um conjunto de $n \mathrm{x}$ T observações.

Segundo Hsiao (1986), uma das principais vantagens da modelagem em painel é a possibilidade de analisar os dados por meio de cortes transversais ou temporais separadamente ou em conjunto, além de ser possível controlar com 
maior rigor a heterogeneidade do grupo de empresas analisadas. Assim, esperase controlar os efeitos das variáveis não observadas, evitando resultados viesados. Outra vantagem da modelagem está na maior eficiência, aumentando os graus de liberdade e, conseqüentemente, diminuindo o problema de multicolinearidade entre as variáveis explicativas.

O modelo de efeitos fixos permite controlar os efeitos das variáveis omitidas que oscilam de empresa para empresa (por exemplo, capacidade dos gestores), mas que apresentam uma tendência constante no decorrer do tempo T. Para isso, supõe-se que o intercepto $\beta_{0}$ varie de empresa para empresa, mas permaneça constante no decorrer desse mesmo tempo T. Em contrapartida, os parâmetros respostas serão constantes tanto no decorrer do tempo como de empresa para empresa.

O modelo de efeitos aleatórios se diferencia do modelo de efeitos fixos pelo tratamento dado ao intercepto. Dessa vez, considera-se uma variável aleatória no modelo. Ou seja, considera-se nesta especificação que as empresas analisadas são uma amostra aleatória representativa de uma população maior de empresas.

A escolha do modelo mais adequado deu-se por intermédio dos testes do multiplicador de Lagrange e de Hausman. A estatística do multiplicador de Lagrange testa a influência ou não de efeitos individuais na amostra em questão. Caso a hipótese nula não seja rejeitada, o modelo mais simples, sem efeitos individuais, será o mais adequado. Já a estatística de Hausman verifica se os efeitos aleatórios ou os fixos são os mais adequados para a especificação do modelo. Para essa estatística, a rejeição da hipótese nula pode ser interpretada como o modelo de efeitos fixos mais adequado. Além desses testes, foram consideradas na análise as estatísticas $\mathrm{F}, \mathrm{R}^{2} \mathrm{e}$ t.

\section{RESULTADOS}

\section{ANÁLISE DESCRITIVA}

Foram utilizadas três variáveis básicas para compreender o estado de financiamento das empresas, o endividamento bruto da empresa ( $\left.\Delta E n d \_b r u t o\right)$, as emissões de ações da empresa a valores contábeis (dSB) e o déficit financeiro da empresa (DEF), conforme definições apresentadas na metodologia.

Na Tabela I, apresentam-se as estatísticas descritivas dessas variáveis para a amostra total e classificada segundo o tamanho, a lucratividade e o cres- 
cimento. Considerando toda a amostra, a média do déficit financeiro foi de ○,03I (3,I\%) para cada unidade de ativo total. Já a média de endividamento bruto foi de 0,045 para cada unidade de ativo total e a média do lucro operacional da empresa foi de 0,060 por unidade de ativo. Já a emissão de ações segundo valores contáveis alcançou uma média, estatisticamente diferente de zero, de 0,037 por unidade de ativo, embora a mediada seja muito menor $(0,006)$. As observações que envolvem essas análises variaram entre I822 e I834. Os maiores desvios padrão verificados foram para o déficit financeiro das empresas $(0,52)$ e para o endividamento bruto $(0,50)$, o que revela a grande heterogeneidade das características das empresas brasileiras. Já os menores desvios padrão verificados corresponderam ao lucro operacional das empresas $(\mathrm{O}, \mathrm{II})$ e à emissão de ações - dSB (O,I64).

Quando se comparam as médias das variáveis mencionadas, percebe-se uma diferença estatística significativa entre as categorias das empresas, definidas com base no tamanho, na lucratividade e no crescimento. Percebe-se também que, em geral, as empresas de menor tamanho na amostra, de menor lucratividade e de baixo crescimento apresentam maior desvio padrão nas variáveis analisadas (Tabela I). Tais características revelam a importância de uma metodologia que reconheça essa heterogeneidade.

\subsection{ANÁLISE EMPÍRICA DA POT}

Como no trabalho foram realizadas diversas regressões, com subamostras definidas de acordo com as características das empresas, a escolha do modelo apropriado para a análise foi feita com base nos testes calculados para a regressão, considerando toda a amostra (Tabela 2). Nessa, com base na estatística do multiplicador de Lagrange, a hipótese nula foi rejeitada, ou seja, há diferenças significativas entre modelos com e sem efeitos individuais. Dessa forma, a utilização do modelo de dados em painel está justificada, o que revela que as características de cada empresa exercem uma importante influência na definição do seu endividamento e financiamento do déficit financeiro (por limitações de espaço, esses coeficientes não são apresentados nos resultados das regressões). Quanto à estatística de Hausman, a hipótese nula também foi rejeitada para o modelo geral, fazendo com que o modelo de efeitos fixos fosse considerado em todo o trabalho por ser o único estimador consistente. 
TABELA I

ANÁLISE DESCRITIVA DAS PRINCIPAIS VARIÁVEIS UTILIZADAS NO ESTUDO: 2000-2005

\begin{tabular}{|c|c|c|c|c|c|c|}
\hline & DEF & $\Delta$ End_bruto & $d S B$ & $\Delta R E$ & $\Delta \mathrm{A}$ & $\mathrm{dE}$ \\
\hline \multicolumn{7}{|l|}{ Geral } \\
\hline Média & 0,0312 & 0,0448 & 0,0369 & $-0,0449$ & $-0,0180$ & 0,0601 \\
\hline Mediana & $-0,0035$ & 0,0086 & 0,0059 & 0,0000 & $-0,0123$ & 0,0675 \\
\hline Desvio padrão & 0,5194 & 0,5042 & 0,1640 & 0,4673 & 0,2267 & 0,1075 \\
\hline Tamanho 1* & $(0,1340)$ & $(0,0048)$ & $(0,3954)$ & $(0,0019)$ & $(0,0000)$ & $(0,0000)$ \\
\hline Média & 0,0494 & 0,0782 & 0,0337 & $-0,0791$ & $-0,0405$ & 0,0299 \\
\hline Desvio padrão & 0,7030 & 0,7031 & 0,2060 & 0,6546 & 0,2486 & 0,1239 \\
\hline \multicolumn{7}{|l|}{ Tamanho 2} \\
\hline Média & 0,0130 & 0,0117 & 0,0402 & $-0,0109$ & 0,0044 & 0,0903 \\
\hline Desvio padrão & 0,2136 & 0,1132 & 0,1065 & 0,0847 & 0,2004 & 0,0773 \\
\hline Lucratividade $1^{*}$ & $(0,0000)$ & $(0,0000)$ & $(0,0033)$ & $(0,0000)$ & $(0,0000)$ & $(0,0000)$ \\
\hline Média & 0,1453 & 0,1467 & 0,0420 & $-0,1916$ & $-0,0736$ & $-0,0683$ \\
\hline Desvio padrão & 1,0106 & 1,0345 & 0,2985 & 0,9606 & 0,2883 & 0,1056 \\
\hline \multicolumn{7}{|l|}{ Lucratividade 2} \\
\hline Média & $-0,0132$ & 0,0202 & 0,0210 & $-0,0084$ & $-0,0286$ & 0,0530 \\
\hline Desvio padrão & 0,2458 & 0,1314 & 0,0899 & 0,0991 & 0,2266 & 0,0515 \\
\hline \multicolumn{7}{|l|}{ Lucratividade 3} \\
\hline Média & 0,0094 & 0,0106 & 0,0497 & 0,0028 & 0,0241 & 0,1409 \\
\hline Desvio padrão & 0,1875 & 0,1095 & 0,0978 & 0,0826 & 0,1730 & 0,0677 \\
\hline Crescimento 1 * & $(0,0273)$ & $(0,1978)$ & $(0,0001)$ & $(0,0001)$ & $(0,0000)$ & $(0,0000)$ \\
\hline Média & 0,0032 & 0,0608 & 0,0214 & $-0,0907$ & $-0,1054$ & 0,0316 \\
\hline
\end{tabular}


TABELA I (CONTINUAÇÃO)

ANÁLISE DESCRITIVA DAS PRINCIPAIS VARIÁVEIS UTILIZADAS

NO ESTUDO: 2000-2005

\begin{tabular}{crrrrrr}
\hline & \multicolumn{1}{c}{ DEF } & \multicolumn{1}{c}{$\Delta$ End_bruto } & \multicolumn{1}{l}{ dSB } & \multicolumn{1}{l}{$\Delta$ RE } & \multicolumn{1}{c}{$\Delta \mathrm{A}$} & \multicolumn{1}{c}{$\mathrm{dE}$} \\
\hline Desvio padrão & 0,7090 & 0,7152 & 0,1675 & 0,6528 & 0,2491 & 0,1153 \\
\hline Crescimento 2 & & & & & & \\
\hline Média & 0,0579 & 0,0297 & 0,0517 & $-0,0016$ & 0,0647 & 0,0875 \\
\hline Desvio padrão & 0,2161 & 0,0945 & 0,1594 & 0,1346 & 0,1654 & 0,0917 \\
\hline No observações $^{0}$ & 1.834 & 1.834 & 1.828 & 1.822 & 1.822 & 1.832 \\
\hline
\end{tabular}

*Os valores entre parênteses correspondem ao valor p do teste $t$ para a comparação das médias de tamanho e crescimento, e do teste $\mathrm{F}$ no caso da lucratividade, de cada variável respectivamente.

Fonte: Elaborada pelos autores.

\subsubsection{Financiamento do déficit na amostra completa}

Nesta seção da pesquisa, analisam-se as características do endividamento e da emissão de ações para a amostra como um todo. O coeficiente do déficit financeiro da empresa para explicar o endividamento total foi 0,636 . Ou seja, para cada unidade de déficit financeiro da empresa, 0,636 foi financiado com emissão de dívida por parte das empresas. Na análise desses dados, o beta encontrado difere estatisticamente de o e de I. Disso é possível concluir que, considerando a amostra como um todo, as empresas ferem o pressuposto básico da POT que afirma que o coeficiente da regressão deveria ser igual a I $\left(\beta_{1}=1\right)$. Neste primeiro modelo, foram significativas as dummies para os anos de 2002 e 2003 , o que revela a importância destes para uma correta explicação do financiamento do déficit das empresas (Tabela 2).

Com relação às emissões de ações (dSB), percebeu-se uma sensível diferença entre a média e a mediana. Ou seja, em uma análise completa da amostra têmse valores discrepantes (outliers) que distorcem a média. Assim, considerando a mediana da série, observa-se que, do patrimônio da empresa não financiado pela retenção de lucros, o equivalente a 0,594\% do ativo foi financiado por novas emissões de ações. Contudo, no nível de 5\%, rejeita-se a hipótese de que a média seja o contradizendo a POT. Essa conclusão foi obtida a partir de uma amostra de r.828 observações e com um desvio padrão de o,I640. 


\section{TABELA 2}

\section{ANÁLISE DO ENDIVIDAMENTO BRUTO DAS EMPRESAS}

PARA TODA A AMOSTRA

\begin{tabular}{lc}
\hline Endividamento bruto & Modelo geral (fe) \\
\hline DEF & $0,636(40,98)^{\star *}$ \\
\hline Ilano_2002 & $0,062(3,31)^{* *}$ \\
\hline lano_2003 & $0,057(3,06)^{\star *}$ \\
\hline Constante & $-0,009(-0,65)$ \\
\hline R & 0,53 \\
\hline Observações $=1.834$ & $N^{\circ}$ empresas $=313$ \\
\hline Prob (F) $=0,000$ & Prob $\left(\right.$ Ho: $\left.\beta_{1}=1\right)=0,000$ \\
\hline Teste de Lagrange & $188,47^{* *}$ \\
\hline Teste de Hausman & $195,08^{* *}$ \\
\hline
\end{tabular}

Valores da estatística t entre parênteses; * significante a 5\%; $* *$ significante a I\%.

Fonte: Elaborada pelos autores.

\subsubsection{Financiamento do déficit e efeito do tamanho da empresa}

Nesta seção, discute-se o comportamento da estrutura de financiamento da empresa condicionada a fatores de tamanho dela. Os ativos totais foram utilizados para a classificação das empresas como médias ou grandes, como já explicitado anteriormente.

O modelo de regressão foi estimado para cada grupo especificado por tamanho. Observou-se que as médias empresas (tamanho I) tendem a se endividar mais para financiar as suas atividades do que as grandes empresas (tamanho 2) - como é previsto pelo modelo. Nas médias empresas (Tabela 3), para cada unidade de déficit financeiro 0,698 dela foi financiado por emissão de dívida. Estatisticamente esse coeficiente calculado foi diferente de o e de I, e o modelo apresenta um grau de ajuste de $56 \%\left(\mathrm{R}^{2}\right)$. Nesse modelo, os anos de $2002,2003 \mathrm{e}$ 2004 foram significativos. Em termos de emissão de ações, as médias empresas, de acordo com a mediana encontrada, não emitem ações para financiar as suas 
atividades. Entretanto, a média (Tabela I) foi estatisticamente diferente de o e indica que o equivalente a 3,36\% do ativo foi financiado por emissões de ações (com um desvio padrão de 0,2059 ). Pode-se concluir que, entre as médias empresas, apesar dos altos custos de emissão das ações e da possível existência de assimetria informacional que essa emissão poderia gerar, algumas delas utilizam-se desse recurso.

TABELA 3

ANÁLISE DO ENDIVIDAMENTO BRUTO DAS EMPRESAS SEGUNDO O TAMANHO DOS ATIVOS DELAS

\begin{tabular}{lcc}
\hline Endividamento bruto & Tamanho 1 (fe) & Tamanho 2 (fe) \\
\hline DEF & $0,698(30,46)^{\star *}$ & $0,319(18,64)^{\star *}$ \\
\hline _lano_2002 & $0,086(2,46)^{*}$ & $0,025(2,39)^{\star}$ \\
\hline _lano_2003 & $0,093(2,62)^{\star *}$ & $-0,014(-1,25)$ \\
\hline _lano_2004 & $0,087(2,44)^{\star}$ & $-0,036(3,35)^{\star *}$ \\
\hline Constante & $-0,016(-0,63)$ & $0,012(-1,58)$ \\
\hline Observações & 916 & 918 \\
\hline Número de empresas & 166 & 167 \\
\hline R & 0,56 & 0,38 \\
\hline Prob (F) & 0,000 & 0,000 \\
\hline Prob (Ho: $\left.\beta_{1}=1\right)$ & 0,000 & 0,000 \\
\hline
\end{tabular}

Valores da estatística t entre parênteses; * significante a $5 \%$; ** significante a I\%.

Fonte: Elaborada pelos autores.

Como já mencionado, as grandes empresas se endividam menos do que as médias empresas e emitem mais ações que essas últimas. Esse fato está relacionado à enorme capacidade das grandes empresas para gerar lucros suficientes para financiar as suas atividades e à boa imagem da empresa no mercado, o que ameniza os efeitos da assimetria informacional no valor patrimonial da empresa. Em termos de endividamento (Tabela 3), para cada unidade de déficit financeiro não financiado por recursos internos, 0,319 foi patrocinado por 
emissão de dívidas. Para as emissões de ações, as grandes empresas emitem mais do que as médias empresas em termos percentuais, mas não existe diferença estatística entre as duas médias (Tabela I). A diferença entre a média e a mediana das emissões de ações já não foi tão discrepante, o que reafirma a importância das emissões de ações para esse grupo de empresas. Em média, das variações do patrimônio não financiadas pela retenção de lucros, o equivalente a 4,0\% do ativo foi financiado pela emissão de ações, uma importância estatisticamente significativa.

\subsubsection{Financiamento do déficit e efeito da lucratividade}

O conjunto de empresas analisadas também se diferencia por suas características de lucratividade. Nesta classificação, busca-se captar a capacidade da empresa em gerar lucros suficientes para financiar as suas atividades. Como indicado na metodologia, o Ebit das empresas foi utilizado para classificar essa capacidade de geração de lucros.

Para as empresas com lucratividade negativa (Lucr I), o nível de endividamento foi consideravelmente maior do que para os outros grupos considerados. Para cada unidade de déficit financeiro não financiado por recursos internos, 0,768 deste foi financiado por meio de emissões de dívida pela empresa, sendo esse coeficiente diferente de o e de I. Para essa regressão, somente a dummy para o ano de 2002 apresentou relevância estatística (Tabela 4).

\section{TABELA 4}

ANÁLISE DO ENDIVIDAMENTO BRUTO DAS EMPRESAS SEGUNDO A LUCRATIVIDADE DELAS

\begin{tabular}{lccc}
\hline Endividamento bruto & Lucr $1(\mathrm{fe})$ & $\operatorname{Lucr} 2(\mathrm{fe})$ & $\operatorname{Lucr} 3(\mathrm{fe})$ \\
\hline DEF & $0,768(22,88)^{\star *}$ & $0,247(13,81)^{\star *}$ & $0,316(14,25)^{\star *}$ \\
\hline _lano_2002 & $0,161(2,25)^{*}$ & $0,023(-1,82)$ & $0,026(2,14)^{\star}$ \\
\hline _lano_2004 & $0,144(-1,87)$ & $-0,021(-1,46)$ & $-0,028(2,17)^{\star}$ \\
\hline Ilano_2005 & $0,061(-0,77)$ & $-0,039(2,69)^{* *}$ & $0,009(-0,71)$ \\
\hline Constante & $-0,064(-1,23)$ & $0,033(3,45)^{\star *}$ & $0,005(-0,62)$ \\
\hline Observações & 412 & 706 & 716 \\
\hline
\end{tabular}




\section{TABELA 4 (CONTINUAÇÃO)}

ANÁLISE DO ENDIVIDAMENTO BRUTO DAS EMPRESAS SEGUNDO A LUCRATIVIDADE DELAS

\begin{tabular}{lccc}
\hline Endividamento bruto & Lucr 1 (fe) & Lucr 2 (fe) & Lucr 3 (fe) \\
\hline Número de empresas & 89 & 173 & 163 \\
\hline$R^{2}$ & 0,63 & 0,29 & 0,31 \\
\hline Prob (F) & 0,00 & 0,00 & 0,00 \\
\hline Prob (Ho: $\left.\beta_{1}=1\right)$ & 0,00 & 0,00 & 0,00 \\
\hline
\end{tabular}

Valores da estatística t entre parênteses; * significante a $5 \%$; ** significante a I\%.

Fonte: Elaborada pelos autores.

Considerando as emissões de ações, de acordo com a mediana de ०,००\%, as variações do patrimônio foram plenamente financiadas pelos lucros retidos. Entretanto, uma média positiva significativa e um desvio padrão de 0,2985 (Tabela I) evidenciam a existência de empresas que, mesmo passando por dificuldades de geração de lucros (em termos reais), emitem ações. Essa atitude por parte das empresas as expõe a riscos em razão das já mencionadas assimetrias informacionais, expondo o patrimônio dos acionistas.

Para as empresas com baixa lucratividade, mas positiva (Lucr 2), a emissão de dívida como forma de financiamento do déficit financeiro da empresa, de acordo com o coeficiente da regressão (Tabela 4), mostra que para cada unidade do déficit há um financiamento de 0,247 por meio de endividamento - sendo este coeficiente calculado estatisticamente diferente de o e de I. A média de emissão de ações (Tabela I) também foi estatisticamente significativa na formação do patrimônio. Já a mediana mostra que, da variação do patrimônio da empresa não financiado pelos lucros retidos, o equivalente do ativo de apenas $0,05 \%$ foi financiado por meio das emissões de ações. Esse resultado mostra uma realidade brasileira, a dificuldade de as empresas conseguirem o financiamento das atividades empresariais. As empresas com baixa capacidade de retenção de lucro e de geração de recursos internos para o financiamento das atividades empresariais não têm fácil acesso ao crédito. Fato este que pode impedir o crescimento da empresa e até dificultar o seu funcionamento.

As empresas com alta lucratividade (Lucr 3) foram as que apresentaram maior capacidade de retenção de lucro e de geração de recursos para o financia- 
mento de suas atividades. Estas apresentaram maior nível de endividamento, quando comparado às empresas de baixa lucratividade, em razão de sua maior capacidade de captação de recursos no mercado de crédito brasileiro. Ou seja, para cada unidade de déficit financeiro não financiado por recursos internos, 0,3i6 foi financiado pela emissão de dívida (Tabela 4). Para as emissões de ações como forma de financiamento, da variação do patrimônio não financiado com recursos internos, estas realizam, de acordo com a sua mediana, emissão de ações equivalentes a 3,09\% do ativo. Embora a média de emissão de ações (Tabela I) não seja estatisticamente significativa, o fato de essa variável possuir um desvio padrão de 0,978 indica que, na amostra considerada, há uma parcela de empresas que utilizam a alternativa de emissões de ações como meio de financiamento. Esse comportamento era esperado, já que, no mercado de capitais, as empresas com maior capacidade de geração de lucro são as mais atrativas para acionistas potenciais, embora elas não realizem emissões de ações com tanta freqüência.

\subsubsection{Financiamento do déficit e efeito do crescimento dos ativos}

Separar a amostra de acordo com as características de crescimento dos ativos é necessário, pois essa é uma característica de grande relevância para as decisões por formas de financiamento das atividades empresariais. Para isso, utilizou-se o ativo total das empresas como variável classificadora.

As empresas com baixo crescimento de seus ativos (Cresc i) foram as que mais se utilizam do endividamento como forma de financiamento do seu déficit financeiro. O coeficiente encontrado mostra que, para cada unidade de déficit não financiado por recursos internos, 0,767 foi financiado por emissão de dívidas (Tabela 5). Para essa análise, os anos de 2002, 2003 e 2004 foram significativos. De acordo com a média (significativa estatisticamente), algumas empresas desse grupo utilizam as emissões de ações como forma de captação de recursos (Tabela I), embora a mediana da dSB para esse grupo tenha sido de $\circ, 0 \circ \%$, corroborando as dificuldades das empresas com essa característica de emitir ações.

Já as empresas com alto crescimento dos seus ativos apresentaram uma baixa utilização do endividamento como forma de financiamento de suas atividades, sendo o coeficiente somente o,I85 para cada unidade de déficit financeiro gerado. Esse fato explica-se devido à capacidade destas empresas de gerar recursos para 
um autofinanciamento. Empresas com alto crescimento dos ativos geralmente apresentam altas taxas de lucratividade, fato esse diretamente relacionado com a sua capacidade de financiamento.

Além disso, empresas com alto crescimento dos ativos também possuem maiores condições de emitir ações no mercado de capitais (a média foi estatisticamente significativa), com uma redução dos efeitos negativos decorrentes da assimetria informacional. Considerando a mediana - que não sofre fortes impactos da existência de outliers na amostra -, as empresas com maior crescimento captam $2,4 \mathrm{I} \%$ do seu ativo com a emissão de ações no mercado de capitais. Pode-se concluir para esse grupo de empresas que a emissão de ações foi uma alternativa interessante de captação de recursos para o financiamento de investimentos.

\section{TABELA 5}

ANÁLISE DO ENDIVIDAMENTO BRUTO DAS EMPRESAS SEGUNDO O CRESCIMENTO DOS ATIVOS DELAS

\begin{tabular}{lcc}
\hline Endividamento bruto & Cresc $1(\mathrm{fe})$ & Cresc $2(\mathrm{fe})$ \\
\hline DEF & $0,767(32,31)^{\star *}$ & $\begin{array}{c}0,185 \\
(12,61)^{* *}\end{array}$ \\
\hline _lano_2002 & $0,113(3,20)^{* *}$ & $0,015(-1,65)$ \\
\hline _lano_2003 & $0,112(2,79)^{* *}$ & $-0,006(-0,56)$ \\
\hline _lano_2004 & $0,12(2,97)^{* *}$ & $-0,008(-0,79)$ \\
\hline Constante & $-0,015(-0,56)$ & $0,014(-1,91)$ \\
\hline Observações & 895 & 939 \\
\hline Número de empresas & 224 & 231 \\
\hline R & 0,61 & 0,21 \\
\hline Prob (F) & 0,00 & 0,00 \\
\hline Prob (Ho : $\left.\beta_{1}=1\right)$ & 0,00 & 0,00 \\
\hline
\end{tabular}

Valores da estatística t entre parênteses; * significante a $5 \%$; $* *$ significante a $\mathrm{I} \%$. 


\subsubsection{Análise da combinação de características}

Nesta última seção, analisam-se as empresas de acordo com as suas características conjugadas. Foram formados doze grupos de análise, combinando as categorias estabelecidas para as características de tamanho, lucratividade e crescimento dos ativos (FAMA; FRENCH, 2005). A distribuição das empresas de acordo com os diferentes grupos é apresentada na Tabela 6 :

\section{TABELA 6}

DISTRIBUIÇÃO DAS EMPRESAS SEGUNDO AS CARACTERÍSTICAS ANALISADAS

\begin{tabular}{|l|c|c|c|c|c|c|c|c|c|c|c|c|c|}
\hline Tamanho (AT) & \multicolumn{4}{c}{ Médias empresas } & \multicolumn{5}{c|}{ Grandes empresas } \\
\hline Lucratividade (E) & Negativa & Baixa & Alta & Negativa & Baixa & \multicolumn{2}{c|}{ Alta } \\
\hline Crescimento (dA) & Baixo & Alto & Baixo & Alto & Baixo & Alto & Baixo & Alto & Baixo & Alto & Baixo & Alto \\
\hline Grupo & 1 & 2 & 3 & 4 & 5 & 6 & 7 & 8 & 9 & 10 & 11 & 12 \\
\hline
\end{tabular}

Fonte: Elaborada pelos autores.

Para obter resultados consistentes e menos influenciados pelo número de observações, os grupos 2, 5, 7 e 8 foram excluídos para a análise econométrica desta seção.

Com relação ao endividamento bruto das empresas (Tabela 7), somente as empresas do grupo I se aproximaram mais da proposta da POT, apresentando um coeficiente de endividamento de 0,888 para cada unidade de déficit financeiro. O segundo grupo com maior coeficiente do déficit foi o grupo II, mas esse coeficiente encontra-se abaixo das predições da POT, sendo o,488 para cada unidade de déficit financeiro. Os outros grupos apresentaram coeficientes baixos - com coeficiente médio de endividamento de 0,25 para cada unidade de déficit financeiro -, contrariando os pressupostos da POT e corroborando a possível não-existência da POT na atualidade. As empresas do grupo I, únicas que apresentaram características de acordo com a POT, possivelmente se utilizam do endividamento por sua dificuldade de retenção de lucros e, conseqüentemente, de autofinanciamento. Essas empresas foram de lucratividade negativa e de baixo crescimento dos seus ativos, características que justificam o alto endividamento destas e a baixa emissão de ações no mercado (Tabela 8). 
TABELA 7

ANÁLISE DO ENDIVIDAMENTO BRUTO DAS EMPRESAS SEGUNDO COMBINAÇÕES DAS CARACTERÍSTICAS DELAS

\begin{tabular}{|c|c|c|c|c|c|c|c|}
\hline & DEF & Constante & Observações & $\begin{array}{c}\mathrm{N}^{\circ} \\
\text { empresas }\end{array}$ & $\mathrm{R}^{2}$ & Prob (F) & $\begin{array}{c}\text { Prob (Ho: } \\
\beta_{1}=1 \text { ) }\end{array}$ \\
\hline Grupo 1 & $0,888(20,9)^{* *}$ & $-0,093(-1,2)$ & 245 & 61 & 0,72 & 0,000 & 0,009 \\
\hline Grupo 3 & $0,201(3,8)^{* *}$ & $0,038(-1,1)$ & 190 & 56 & 0,12 & 0,008 & 0,000 \\
\hline Grupo 4 & $0,199(6,0)^{* *}$ & $0,022(-1,1)$ & 133 & 41 & 0,31 & 0,000 & 0,000 \\
\hline Grupo 6 & $0,309(10,6)^{* *}$ & $-0,003(-0,3)$ & 187 & 51 & 0,51 & 0,000 & 0,000 \\
\hline Grupo 9 & $0,27(13,4)^{* *}$ & $0,027(2,1)^{*}$ & 202 & 60 & 0,61 & 0,000 & 0,000 \\
\hline Grupo 10 & $0,243(7,1)^{\star *}$ & $0,024(-1,8)$ & 181 & 56 & 0,33 & 0,000 & 0,000 \\
\hline Grupo 11 & $0,488(6,1)^{* *}$ & $0,08(-1,2)$ & 144 & 48 & 0,34 & 0,000 & 0,000 \\
\hline Grupo 12 & $0,263(10,6)^{* *}$ & $0,00(-0,0)$ & 306 & 77 & 0,42 & 0,000 & 0,000 \\
\hline
\end{tabular}

Valores da estatística t entre parênteses; *significante a 5\%; **significante a I\%.

Fonte: Elaborada pelos autores.

Caracterizando as empresas de acordo com o resultado da emissão de ações - dSB (Tabela 8) -, os grupos que apresentaram menores discrepâncias entre as suas médias e medianas foram os grupos 6 e I2. Para o grupo 6 , da variação do patrimônio não financiado pelos lucros retidos, o equivalente a 6,16\% do ativo foi financiado por emissão de ações. Para as empresas do grupo I2, esse valor representa $6,22 \%$. Para os outros grupos, as diferenças entre as médias e medianas foram significativas, assim a análise considerou as medianas. O grupo 3 destacou-se por apresentar uma emissão de ações negativa (recompra de ações), ou seja, a variação do patrimônio foi financiada por recursos internos da empresa. Já os grupos I e 9 não apresentam (de acordo com as medianas) emissões de ações para o financiamento do déficit. E, mesmo considerando a média, a quantidade de emissão foi muito baixa (equivalente a 3,23\% e I,78\% do ativo, respectivamente). Todos os grupos apresentados possuem mais de cem observações e desvios padrão que variam de 0,2877 a 0,0595. 
TABELA 8

ANÁLISE DESCRITIVA DAS EMISSÖES DE AÇŐES

A VALORES CONTÁBEIS SEGUNDO COMBINAÇÕES

DE CARACTERÍSTICAS DAS EMPRESAS

\begin{tabular}{lcccccccc}
\hline & GRUPO 1 & GRUPO 3 & GRUPO 4 & GRUPO 6 & GRUPO 9 & GRUPO 10 & GRUPO 11 & GRUPO 12 \\
\hline Média & 0,0323 & 0,0060 & 0,0378 & 0,0616 & 0,0178 & 0,0280 & 0,0225 & 0,0622 \\
\hline Mediana & 0,0000 & $-0,0002$ & 0,0025 & 0,0394 & 0,0000 & 0,0056 & 0,0081 & 0,0416 \\
\hline Desvio padrão & 0,2877 & 0,0870 & 0,1011 & 0,1198 & 0,0922 & 0,0787 & 0,0595 & 0,1002 \\
\hline Observações & 245 & 190 & 133 & 187 & 202 & 181 & 141 & 307 \\
\hline
\end{tabular}

Fonte: Elaborada pelos autores.

\section{CONSIDERAÇÕES FINAIS}

O presente estudo visou verificar se as empresas brasileiras se enquadram às predições da Pecking Order Theory (POT). Diversos estudos, em sua maioria, confirmaram as previsões da POT. Entretanto, Fama e French (2005), utilizando uma metodologia distinta, questionaram a existência da POT como teoria válida para explicar a estrutura de capital das empresas, porque as emissões de ações são mais freqüentes do que a previsão dessa teoria. A limitação das metodologias anteriores estaria na desconsideração das características das empresas, fazendo a verificação da POT como se a amostra fosse homogênea (agrupamento de empresas com características diversas). Além disso, também pode ser destacada a dificuldade de acesso ao mercado de crédito de longo prazo no Brasil, o que obriga as empresas a utilizarem a dívida de curto prazo para financiamento de investimentos.

Esta pesquisa propôs uma nova metodologia para a verificação da POT no mercado brasileiro, fundamentada nas propostas de Shyam-Sunder e Myers (1999), Frank e Goyal (2003) e Fama e French (2005). Basicamente, consiste na utilização de um modelo de dados em painel, reconhecendo algumas características diferenciadas das empresas e considera o endividamento bruto na análise, e não somente a dívida de longo prazo.

Dentre as principais características observadas tem-se, para uma análise da amostra geral, um baixo coeficiente de déficit (para cada unidade de déficit financeiro, as empresas o financiam com o,636 de emissão de dívida); e a emissão de ações a valores contábeis também é relativamente baixa, mas estatisticamente distinta de o. Considerando as empresas categorizadas de acordo com as suas características de tamanho, em médias e grandes empresas, as primeiras foram 
as que mais se endividaram, e as grandes, aquelas que mais utilizaram a emissão de ações como fonte de financiamento do déficit.

$\mathrm{Na}$ análise das empresas, de acordo com a lucratividade delas, aquelas com lucros operacionais negativos foram as que mais financiaram seu déficit com endividamento - comportamento previsto pela POT. Diante de um lucro operacional negativo, elas possuem baixas (ou quase nulas) condições de autofinanciamento. Já as empresas que apresentaram menor coeficiente para o déficit foram aquelas com lucratividade média. As empresas mais lucrativas foram as que apresentaram maiores indicadores de emissões de ações, tanto em termos de sua média como em termos de sua mediana. Apesar da fraca aderência das empresas com lucratividade negativa, em geral o valor dos coeficientes esteve aquém do previsto na teoria, o que leva a concluir a não-existência da POT.

Quanto ao crescimento dos ativos das empresas, as que mais se endividaram foram as de menor crescimento dos ativos, o que se explica pela dificuldade delas de se autofinanciarem. Já as empresas com alto crescimento dos ativos se destacam pela sua presença no mercado de capitais, por causa de emissões de ações como forma de financiamento.

Como se pode observar, as empresas mais lucrativas, maiores em termos de tamanho e com um elevado crescimento dos seus ativos, foram as que mais buscaram as operações do mercado de capitais como forma de financiamento de seu déficit financeiro.

Segundo as predições do modelo, as médias empresas e as menos lucrativas serão aquelas empresas com maiores tendências a se adequarem aos pressupostos da POT. Neste trabalho, as empresas do grupo I (médias empresas, com lucratividade negativa e baixo crescimento dos ativos) foram as únicas a se adequarem à forma fraca da POT - coeficiente de endividamento acima de o,8 para cada unidade de déficit financeiro e emissões de ações próximas de o. Os outros grupos considerados não se enquadraram ao comportamento previsto pela POT, o que enfraquece a sua existência para o mercado brasileiro e confirma a idéia de Fama e French (2005) de que a POT não pode ser considerada uma teoria da estrutura de capital.

Com base nos resultados, acredita-se na carência de uma explicação teórica consistente para o comportamento das empresas na escolha das formas de financiamento utilizadas. Assim, os questionamentos acerca da POT e da Static Tradeoff parecem favorecer a existência de uma forma híbrida de teorização para as escolhas por formas de financiamento. Ou talvez seja o momento de reconhecer que os gerentes só usam a emissão de ações para financiar projetos quando eles acreditam que as expectativas dos investidores potenciais sobre a rentabilidade do projeto estão provavelmente alinhadas às suas, maximizando assim a probabilidade de acordo com os investidores; caso contrário, eles financiam com a emissão de dívida (DITTMAR; THAKOR, 2007). 
- TESTANDO AS PREVISÕES DA PECKING ORDER THEORY NO FINANCIAMENTO...

\section{REFERÊENCIAS}

AKERLOF, G. A. The market for "lemons": quality uncertainty and the market mechanism. Quarterly Journal of Economics, v. 84, n. 3, p. 488-500, I970.

CHIRINKO, R. S.; SINGHA, A. R. Testing static tradeoff against pecking order models of capital structure: a critical comment. Journal of Financial Economics, v. 58, p. 4I7-425, 2000.

DITTMAR, A.; THAKOR, A. Why do firms issue equity? The Journal of Finance, v. 62, n. I, p. I-54, Feb. 2007.

DONALDSON, G. G. Corporate debt capacity: a study of corporate debt policy and determination of corporate debt capacity. Boston: Harvard Graduate School of Business Administration, I96r.

FAMA, E. F.; FRENCH, K. R. Testing tradeoff and pecking order predictions about dividends and debt. Review of Financial Studies, v. I5, p. I-33, 2002.

Financing decisions: who issues stock? Journal of Financial Economics, v. 76, p. 549-582, 2005 .

FRANK, M. Z.; GOYAL, V. K. Testing the pecking order theory of capital structure. Journal of Financial Economics, v. 67, p. 217-248, 2003.

GITMAN, L. J. Princípios da administração financeira, 7. ed. São Paulo: Harbra, I997.

HARRIS, M.; RAVIV, A. The theory of capital structure. The Journal of Finance, v. 46, n. I, p. 297-355, March I99I.

HSIAO, C. Analysis of panel data. Cambridge: Cambridge University Press, I986.

MEDEIROS, O. R.; DAHER, C. E. Testes empíricos da Pecking Order Theory na estrutura de capital das empresas brasileiras. In: XXVIII ENCONTRO NACIONAL DA ANPAD, 2004, Curitiba. Anais... Curitiba, Anpad, 2004.

MYERS, S. The capital structure puzzle. The Journal of Finance, v. 39, n. 3, p. 575-592, July I984. MYERS, S.; MAJLUF, N. Corporate financing and investment decisions when firms have informations that investors do not have. Journal of Financial Economics, v. I3, p. 187-221, I984.

PEROBELLI, F.; FAMÁ, R. Determinantes da estrutura de capital: Aplicação a empresas de capital aberto brasileiras. Revista de Administração da Universidade de São Paulo, v. 37, n. 3. jul./set., 2002.

SILVA, J. C. G.; BRITO, R. D. Testando as previsões de Trade-offe Pecking Order sobre dividendos e dívida para o Brasil. Estudos Econômicos (IPE/USP), São Paulo, v. 35, n. I, p. 37-79, 2005.

SHYAM-SUNDER, L.; MYERS, S. C. Testing static tradeoff against pecking order models of capital structure. Journal of Financial Economics, v. 51, p. 219-244, I999.

STIGLITZ, J. E.; WEISS, A. Credit rationing with imperfect information. The American Economic Review, v. 7I, n. 3, p. 393-410, I981.

\section{TRAMITAÇ ÃO}

Recebido em 25/6/2007

Aprovado em 15/10/2007 